\title{
Lipopolysaccharide from Escherichia coli Reduces Antigen-induced Bronchoconstriction in Actively Sensitized Guinea Pigs
}

Edouard Vannier, Jean Lefort, Arielle Lellouch-Tubiana, ${ }^{*}$ Bernard Terlain, ${ }^{\star}$ and B. Boris Vargaftig

Unité de Pharmacologie Cellulaire, Unité Associée Institut Pasteur-Institut National de la Santé et de la Recherche Médicale U285, Institut Pasteur, 75015 Paris, France; * Laboratoire d'Histologie, Faculté de Médecine Necker-Enfants Malades, 75015 Paris, France;

${ }^{\ddagger}$ Rhône-Poulenc Rorer, 94400 Vitry-sur-Seine, France

\begin{abstract}
Bronchoconstriction (BC) is the main feature of anaphylaxis in the guinea pig. Since LPS induces lung inflammation and antigen-induced BC depends on the endogenous formation of histamine and arachidonate metabolites, we studied whether LPS might modulate antigen-induced BC. Guinea pigs were sensitized subcutaneously with $10 \mu \mathrm{g}$ ovalbumin (OA) on days 0 and 14. LPS $(100 \mu \mathrm{g} / \mathrm{kg})$ was injected intravenously on day 21 , and daily injections of LPS were continued before the antigenic challenge on day 22, 23, 24, or 25 . Intratracheal injection of 100 $\mu \mathrm{g} \mathrm{OA}$ induced an abrupt and reversible BC. Single or repetitive injections of LPS reduced BC. LPS is likely to reduce the $O A$-induced $B C$ by affecting the histamine-dependent component of BC, since (a) LPS induced a partial degranulation of lung mast cells; (b) BC is reduced by mepyramine, an histamine receptor antagonist; (c) LPS did not affect $B C$ in mepyraminetreated guinea pigs; $(d)$ LPS reduced histamine release by OAstimulated guinea pig lungs in vitro. Moreover, the in vitro OA-induced production of arachidonate metabolites was also reduced by LPS. The decreased formation of $\mathrm{TXB}_{2}$ was not only secondary to a reduced release of histamine, since LPS inhibited $\mathrm{TXB}_{2}$ formation in the presence of mepyramine. Finally, the FMLP-induced $\mathrm{BC}$ and mediator release were inhibited by LPS, whereas the platelet activating factor-induced pulmonary responses were not. Thus, the protective effect of LPS is not antigen-specific and does not result from a general desensitization. These studies indicate that a single dose of LPS reduces the antigen-induced $\mathrm{BC}$ by reducing histamine release from lung mast cells, although a decreased formation of eicosanoids may contribute to the protective effect of LPS. (J. Clin. Invest. 1991. 87:1936-1944.) Key words: FMLP• eicosanoids • histamine $\bullet$ mast cells $\bullet$ platelet activating factor
\end{abstract}

\section{Introduction}

Lipopolysaccharide (endotoxin), the major outer cell wall component of Gram-negative bacteria, is a potent inducer of inflam-

This work was presented in part at the 1989 Annual Meeting of the American Lung Association/American Thoracic Society, Cincinnati, $\mathrm{OH}$.

Address reprint requests to Professor Vargaftig, Institut Pasteur, Unité de Pharmacologie Cellulaire, 25 rue du Dr. Roux, 75015 Paris, France. 1991

Received for publication 2 July 1990 and in revised form 22 January

J. Clin. Invest.

(c) The American Society for Clinical Investigation, Inc.

0021-9738/91/06/1936/09 \$2.00

Volume 87, June 1991, 1936-1944 matory reactions (1-3). Paradoxically, LPS also displays antiinflammatory effects. Thus, a single dose of LPS markedly reduced lethality of mice during septicemia (4) and inhibited the vascular permeability changes and neutrophil exudation induced either in rabbit skin by reverse passive Arthus reaction (5) or in rat pleural cavity by carrageenan $(6,7)$. Furthermore, LPS markedly, but transiently, reduced the local footpad swelling induced by injection of killed Mycobacteria butyricum in rabbits (8). Similarly, Meier et al. (9) reported that a single dose of bacterial polysaccharides derived from Proteus vulgaris protected against death from anaphylactic shock in guinea pigs. Finally, the same preparations inhibited (or suppressed) the active Arthus reaction in guinea pigs (9).

Since the anaphylactic bronchoconstriction results from an immunologically induced inflammatory reaction, we now investigate if the lipopolysaccharide from Escherichia coli O55:B5 modulates the antigen-induced bronchoconstriction in actively sensitized guinea pigs. To characterize further the specificity and mechanism of the protective effect of LPS on anaphylactic bronchoconstriction, lungs isolated from sensitized guinea pigs were stimulated with the antigen, ovalbumin, or with nonantigenic related inflammatory stimuli, such as FMLP and platelet-activating factor (PAF). ${ }^{1}$ We now report that a single intravenous (i.v.) injection of LPS reduces the in vitro bronchoconstriction and mediator release induced by ovalbumin and FMLP, but does not modify the PAF-triggered pulmonary response.

\section{Methods}

Chemicals. The following reagents were purchased: FMLP, histamine, $\mathrm{PGE}_{2}$, 6-keto-PGF ${ }_{1 \alpha}$, thromboxane $\left(\mathrm{TXB}_{2}\right.$ ) (Sigma Chemical Co., St. Louis, MO); lysine acetylsalicylate (Synthélabo Laboratories, Paris, France); mepyramine maleate (Rhône-Poulenc Santé, Vitry-sur-Seine, France); PAF (1-O-hexadecyl-2-acetyl-sn-glycero-3-phosphocholine; Bachem, Bubendorf, Switzerland); pancuronium bromide (Organon, Fresnes, France); chicken ovalbumin (Miles Scientific Div., Naperville, IL). LY171883 was a gift from Dr. J.H. Fleisch (Eli Lilly Research Laboratories, Indianapolis, IN). LPS was purchased from Difco Laboratories Inc., Detroit, MI, and prepared by phenolic extraction (10) from Escherichia coli O55:B5.

Sensitization procedure. $30 \mathrm{~g}$ of aluminum ammonium sulfate (Farmitalia Carlo Erba, Milano, Italy) suspended in $360 \mathrm{ml}$ distilled water was mixed with $150 \mathrm{ml} \mathrm{NaOH} 1 \mathrm{~N}$. This mixture was shaken at room temperature for 30 min until aluminum hydroxide precipitated. The precipitate was centrifuged at $1,500 \mathrm{~g}$ for $15 \mathrm{~min}$ and resuspended in distilled water. $500 \mu \mathrm{l}$ of aluminum hydroxide gel $(40 \mathrm{mg} / \mathrm{ml})$ was mixed with $200 \mu \mathrm{l}$ of ovalbumin solution $(1 \mathrm{mg} / \mathrm{ml})$ at room temperature for $1 \mathrm{~h}$ and then added to $9.3 \mathrm{ml}$ of pyrogen-free saline. Male Hartley guinea pigs (300-350 g; Shamrock, Houdan, France) were in-

1. Abbreviations used in this paper: $\mathrm{BC}$, bronchoconstriction; $\mathrm{OA}$, ovalbumin; PAF, platelet activating factor; PLA $A_{2}$, phospholipase $A_{2}$. 
jected subcutaneously (s.c.) with $0.5 \mathrm{ml}$ of this solution on days 0 and 14.

Pretreatment of guinea pigs with LPS. Nonanesthetized guinea pigs were injected i.v. on day 21 with $100 \mu \mathrm{g} / \mathrm{kg}$ of LPS. Daily injections of LPS were continued until the antigenic provocation with ovalbumin was given on one of the following days, day $22,23,24$, or 25 . In all cases, the final injection of LPS was $24 \mathrm{~h}$ before the antigenic provocation. This pretreatment over $1,2,3$, or $4 \mathrm{~d}$ is referred to as $24,48,72$, or $96 \mathrm{~h}$. Control guinea pigs were similarly injected with pyrogen-free saline.

In vivo anaphylactic shock. Guinea pigs were anesthetized with sodium pentobarbitone (40 mg/kg, intraperitoneal (i.p.); Clin-Midy, Montpellier, France). The trachea was cannulated and ventilation then started with a Palmer miniature respiratory pump (60 strokes/min). Both carotid arteries were cannulated to record the arterial blood pressure (P23Db transducer; Gould Inc., Oxnard, CA) and to collect blood samples for the platelet and leukocyte counts (Counter-ZBI; Coulter Electronics Inc., Hialeah, FL). Drugs were injected into the jugular vein. Guinea pigs were bilaterally vagotomized when drugs were administered through the airways. Spontaneous breathing was abolished with pancuronium bromide, a neuromuscular blocking agent $(4 \mathrm{mg} /$ $\mathrm{kg}$, i.v.) and bronchial resistance to inflation was recorded as previously described (11).

Three hours after the i.p. injection of sodium pentobarbitone, the bronchial reactivity was checked with serotonin (6 $\mu$ g, i.v.; Sigma). Ovalbumin was either infused through the jugular vein at $0.75 \mathrm{mg} / \mathrm{kg}$ (in saline) for $10 \mathrm{~min}$ or injected intratracheally (i.t.) as a bolus of 100 $\mu \mathrm{g}$ in $100 \mu \mathrm{l}$ saline. In the latter case, the airways resistance was not modified by the injection itself. To verify whether ovalbumin was evenly distributed in the airways, cross-sections of lungs from guinea pigs injected i.t. with Evans blue dye were performed $10 \mathrm{~min}$ later and were studded with numerous blue blobs throughout the parenchyma.

Bronchoconstriction is defined as the increase in the bronchial resistance to inflation and is expressed as the area (in square centimeters) above baseline bronchial resistance (i.e., the increased pen displacement over the chart paper) over the 20 -min period starting with either the infusion or the i.t. injection of ovalbumin. The number of circulating platelets and leukocytes was measured before and 1, 3, 5, 10, and 30 min after starting the infusion or after the i.t. injection.

Electron microscopy. Lung blocks $\left(<1 \mathrm{~mm}^{3}\right)$ were fixed for $24 \mathrm{~h}$ in glutaraldehyde (2.5\% in 100 mM PBS, pH 7.4). After washing in PBS, specimens were postfixed in $2 \%$ osmium tetroxide, dehydrated in graded alcohols, and then embedded in Epon 812-filled gelatin capsules. Ultrathin sections were prepared using an ultramicrotome (LKB Instruments, Inc., Gaithersburg, MD) and counterstained with uranyl acetate/lead citrate.

Perfusion of isolated guinea pig lungs. Guinea pigs were anesthetized as above. The trachea was cannulated and the animal was ventilated with a Palmer miniature respiratory pump (60 strokes/min). A thoracotomy was performed and lungs were washed through the cannulated pulmonary artery for $10 \mathrm{~min}$ with $50 \mathrm{ml} \mathrm{Krebs} \mathrm{solution} \mathrm{(118.0}$ $\mathrm{mM} \mathrm{NaCl}, 4.7 \mathrm{mM} \mathrm{KCl}, 2.5 \mathrm{mM} \mathrm{CaCl} \cdot 2 \mathrm{H}_{2} \mathrm{O}, 1.2 \mathrm{mM}$ $\mathrm{MgSO}_{4} \cdot 7 \mathrm{H}_{2} \mathrm{O}, 1.2 \mathrm{mM} \mathrm{KH}_{2} \mathrm{PO}_{4}, 25.0 \mathrm{mM} \mathrm{NaHCO}{ }_{3}, 5.6 \mathrm{mM}$ glucose), containing HSA $(0.25 \%$, wt $/ \mathrm{vol})$. Lungs were rapidly removed, ventilated with a Palmer miniature respiratory pump (40 strokes $/ \mathrm{min}$ ) through the cannulated trachea and immediately perfused $(9 \mathrm{ml} / \mathrm{min}$, $37^{\circ} \mathrm{C}$ ) via the pulmonary artery with a gassed Krebs-HSA solution $\left(95 \% \mathrm{O}_{2}-5 \% \mathrm{CO}_{2}\right)$. Increase in bronchial resistance to inflation were continuously recorded with a Gould P23Db transducer. After a 10-min period of equilibration, increasing doses of ovalbumin $(1 \mathrm{ng}, 100 \mathrm{ng}$, and $10 \mu \mathrm{g}$ ) in $100 \mu \mathrm{l}$ saline were successively administered each 10 -min period via the pulmonary artery. In a separate set of experiments, increasing doses of FMLP or PAF (1 and $100 \mathrm{ng}$ ) were first injected and followed by $10 \mu \mathrm{g}$ of ovalbumin. Histamine, $\mathrm{PGE}_{2}, \mathrm{TXB}_{2}$, 6-keto$\mathrm{PGF}_{1 \alpha}, \mathrm{LTB}_{4}$, and $\mathrm{LTC}_{4}$ were evaluated in the lung effluent collected on ice over each 10 -min period.

Bronchoconstriction is expressed as the area (in square centimeters) above baseline bronchial resistance over a 10-min period starting with each injection of stimulus as described above for the in vitro experiments. Mediator release was appreciated in every 3-min lung effluent fraction following each injection of stimulus.

Histamine assay. A $1-\mathrm{ml}$ aliquot of each lung effluent fraction was mixed with $1 \mathrm{ml}$ of perchloric acid $0.8 \mathrm{~N}$ and centrifuged at $4^{\circ} \mathrm{C}$ for 20 $\min$ at $3,500 \mathrm{rpm}$. Supernatants were stored at $4^{\circ} \mathrm{C}$. Spectrofluorometric assays for histamine were performed according to Lebel (12).

Radioimmunoassays of $T X B_{2}, 6-k e t o-P G F_{1 \alpha}$, and PGE . A 1-ml aliquot of each lung effluent fraction was immediately stored at $-20^{\circ} \mathrm{C}$ for determination of $\mathrm{PGE}_{2}$. Another 1-ml aliquot was kept at room temperature for $60 \mathrm{~min}$, allowing the conversion of $\mathrm{TXA}_{2}$ and $\mathrm{PGI}_{2}$ into their products of transformation $\mathrm{TXB}_{2}$ and 6-keto- $\mathrm{PGF}_{1 \alpha}$, respectively. Every $100-\mu 1$ sample of each lung effluent fraction was incubated overnight at $4^{\circ} \mathrm{C}$ with one of the three ${ }^{125}$ I-labelled prostanoids and its respective antiserum (supplied by Prof. F. Dray, Institut Pasteur, Paris, France). Radiolabelled prostanoids (or their breakdown products) and antisera were dissolved in a phosphate buffer $(100 \mathrm{mM}, \mathrm{pH} 7.4)$ containing bovine $\gamma$-globulin fraction II $(0.3 \%$, wt/vol; Sigma). Bound and free fractions were separated by addition of polyethyleneglycol 6000 ( $30 \%$ in distilled water, Merck, Darmstadt, FRG) and centrifugation at $4^{\circ} \mathrm{C}$ for $10 \mathrm{~min}$ at $4,000 \mathrm{rpm}$. Radioactivity of the pellet (bound fraction) was counted for $1 \mathrm{~min}$ in a gamma counter. The monoclonal antibodies used were $<0.02 \%$ cross-reactive with $\mathrm{PGD}_{2}, \mathrm{PGE}_{2}$,

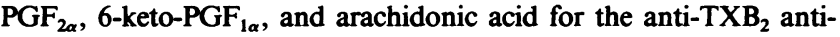
serum; $10.9 \%$ cross-reactive with $\mathrm{PGF}_{2 \alpha}$ and $<2.2 \%$ cross-reactive with $\mathrm{PGD}_{2}, \mathrm{PGE}_{2}$, and $\mathrm{TXB}_{2}$ for the anti-6-keto-PGF ${ }_{1 \alpha}$ antiserum; $<0.11 \%$ cross-reactive with $\mathrm{PGD}_{2}, \mathrm{PGF}_{2 \alpha}$, and $\mathrm{TXB}_{2}$ for the anti-PGE ${ }_{2}$ antiserum. The sensitivities of anti-sera for $\mathrm{TXB}_{2}, \mathrm{PGE}_{2}$, and 6-keto$\mathrm{PGF}_{1 \alpha}$ were 12,20 , and $16 \mathrm{pg}$ in a $100-\mu 1$ sample, respectively.

Radioimmunoassays of $L T B_{4}$ and $L T C_{4}$. A $1-\mathrm{ml}$ aliquot of each lung effluent fraction was immediately stored at $-20^{\circ} \mathrm{C}$. Every $100-\mu 1$ sample of each lung effluent fraction was incubated overnight at $4^{\circ} \mathrm{C}$ with either ${ }^{3} \mathrm{H}$-labelled $\mathrm{LTB}_{4}$ or ${ }^{3} \mathrm{H}$-labelled $\mathrm{LTC}_{4}$ (Amersham International, Amersham, UK), and its respective antiserum. Radiolabelled leukotrienes and antisera were dissolved in a phosphate buffer (100 $\mathrm{mM}, \mathrm{pH}$ 7.4) containing gelatin type I ( $0.1 \%$, wt/vol; Sigma). Bound and free fractions were separated by addition of dextran-coated charcoal (charcoal $0.5 \%$, dextran $0.05 \%$ in phosphate buffer; Sigma) and centrifugation at $4^{\circ} \mathrm{C}$ for $10 \mathrm{~min}$ at $4,000 \mathrm{rpm}$. Supernatants were decanted into scintillation vials and were completed with aqueous counting scintillant ACS-II ( $5 \mathrm{ml}$; Amersham). Vials were counted for $1 \mathrm{~min}$ in a $\beta$ scintillation counter. The monoclonal anti- $\mathrm{LTB}_{4}$ antibody (Amersham) was $0.4 \%$ cross-reactive with $20-\mathrm{OH}-\mathrm{LTB}_{4}$ and 6-trans$\mathrm{LTB}_{4}$, and $<0.05 \%$ with $\mathrm{LTC}_{4}, \mathrm{LTD}_{4}, \mathrm{TXB}_{2}, \mathrm{PGF}_{2 \alpha}, 6-\mathrm{keto} \mathrm{PGF}_{1 \alpha}$ and arachidonic acid. The monoclonal anti-LTC 4 antibody (gift from Dr. U. Zor, Weizmann Institute, Rehovot, Israel) was $10.0 \%$ crossreactive with $\mathrm{LTD}_{4}$ and $<0.1 \%$ with $\mathrm{LTA}_{4}$ and $\mathrm{LTB}_{4}$. Since the anti$\mathrm{LTC}_{4}$ antiserum cross-reacts with $\mathrm{LTD}_{4}, \mathrm{LTC}_{4}$ was reported as immunoreactive $\mathrm{LTC}_{4}\left(\mathrm{iLTC}_{4}\right)$. The sensitivities of antisera for $\mathrm{LTB}_{4}$ and iLTC $_{4}$ were 300 and $150 \mathrm{pg}$ in a $100-\mu l$ sample, respectively.

Statistical analysis. Data were expressed as mean \pm SEM of the indicated number of experiments. Differences between LPS- and salinetreated groups were analyzed for significance by Student's two-tailed $t$ test for unpaired samples. The level of significance was set to $5 \%(P$ $<0.05$ ).

\section{Results}

Pulmonary, hematologic, and hemodynamic effects of LPS in actively sensitized guinea pigs. A rapid and marked peripheral blood leukopenia was induced in sensitized guinea pigs by the i.v. injection of $100 \mu \mathrm{g} / \mathrm{kg}$ LPS (Table I). Number of leukocytes already fell to $50 \%$ (of initial values) at $10 \mathrm{~min}$ and plateaued at $15-25 \%$ from 30 to $120 \mathrm{~min}$ after LPS injection. This marked decrease in leukocyte counts was followed by a slight increase at $180 \mathrm{~min}$. 
Table I. Hemodynamic and Hematologic Effects of LPS Injected Intravenously to Actively Sensitized Guinea Pigs

\begin{tabular}{rlccc}
\hline Time & $\begin{array}{c}\text { Arterial } \\
\text { pressure }\end{array}$ & Hematocrit & Platelets & \multicolumn{1}{c}{ Leukocytes } \\
\hline min & \multicolumn{1}{c}{$m m H g$} & $\times 10^{3} / \mu l$ & $/ \mu l$ & $/ \mu l$ \\
& & & & $13621 \pm 944$ \\
0 & $88.0 \pm 10.7$ & $47.3 \pm 1.3$ & $440 \pm 25$ & $12245 \pm 985$ \\
5 & $75.5 \pm 9.9$ & $47.0 \pm 1.3$ & $444 \pm 21$ & $1026 \pm 1155$ \\
10 & $79.5 \pm 10.6$ & $47.1 \pm 1.5$ & $412 \pm 21$ & $3326 \pm 519$ \\
30 & $87.0 \pm 9.5$ & $47.2 \pm 1.8$ & $395 \pm 27$ & $350 \pm 423$ \\
60 & $68.0 \pm 7.3$ & $48.0 \pm 2.4$ & $374 \pm 28$ & $2050 \pm 423$ \\
120 & $68.0 \pm 10.1$ & $45.2 \pm 2.3$ & $400 \pm 41$ & $3534 \pm 690$ \\
180 & $75.5 \pm 10.7$ & $44.5 \pm 1.8$ & $425 \pm 31$ & $5896 \pm 1064$
\end{tabular}

Arterial pressure, hematocrit values, blood platelet and leukocyte counts were determined before and 5, 10, 30,60,120, and $180 \mathrm{~min}$ after the intravenous injection of $100 \mu \mathrm{g} / \mathrm{kg}$ LPS. Values represent mean \pm SEM of five guinea pigs at each time point.

In these conditions, LPS failed to induce any significant variations in lung resistance to inflation (not shown), arterial pressure, hematocrit values, or circulating platelet counts (Table I).

Inhibition by LPS pretreatment of bronchoconstriction induced by the infusion of ovalbumin. The infusion of ovalbumin $(0.75 \mathrm{mg} / \mathrm{kg})$ over a 10 -min period induced bronchoconstriction in sensitized guinea pigs (Fig. $1 A$ ). Lung resistance to inflation increased after a lag time of $3 \mathrm{~min}$, peaked within 10 min, and slowly recovered over the following $20 \mathrm{~min}$. An abrupt and marked arterial hypotension was recorded after 1 min and was followed within 3-5 min by a hypertensive phase (not shown). Numbers of circulating leukocytes and platelets fell from $1 \mathrm{~min}$ on, and reached their nadir at $5 \mathrm{~min}$ (Table II).

Pretreatment of sensitized guinea pigs with $100 \mu \mathrm{g} / \mathrm{kg}$ LPS prevented antigen-induced bronchoconstriction (Fig. $1 B$ ). Repetitive i.v. injections of LPS (refered to as 48,72 , or $96 \mathrm{~h}$ ) significantly reduced ovalbumin-induced bronchoconstriction, whereas a single i.v. injection $(24 \mathrm{~h})$ was ineffective (Fig. 2). Single or repetitive i.v. injections of LPS failed to prevent

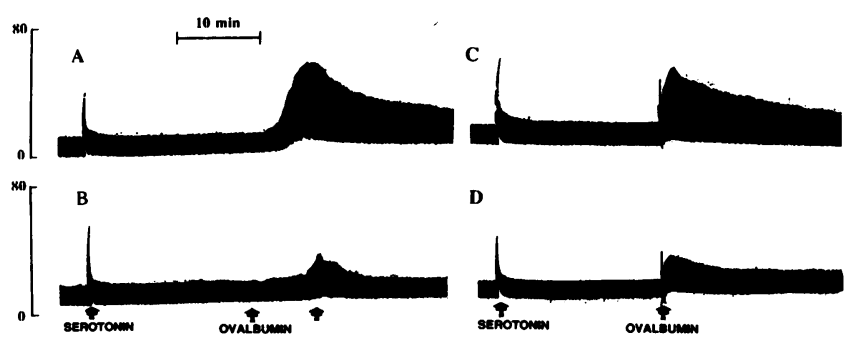

Figure 1. Representative tracings of bronchoconstriction induced by ovalbumin in actively sensitized guinea pigs; effect of i.v. pretreatment with either LPS or saline. Ovalbumin was either infused i.v. for $10 \mathrm{~min}$ at $0.75 \mathrm{mg} / \mathrm{kg}(A, B)$ or injected i.t. as a bolus of $100 \mu \mathrm{g}(C$, $D)$. The bronchial reactivity was checked with serotonin $(6 \mu \mathrm{g}$, i.v.). Guinea pigs were first injected i.v. with $100 \mu \mathrm{g} / \mathrm{kg}$ of LPS $48 \mathrm{~h}(B)$ or $24 \mathrm{~h}(D)$ before the antigenic provocation with ovalbumin. Control guinea pigs $(A, C)$ were injected i.v. with saline $(1 \mathrm{ml} / \mathrm{kg})$ following the same protocol. Arrows indicate the $10 \mathrm{~min}$ infusion of ovalbumin $(A, B)$ or its i.t. injection $(C, D)$. Each tracing is representative of four to nine experiments. Time scale: $10 \mathrm{~min}$; vertical scale: bronchoconstriction in $\mathrm{cm} \mathrm{H}_{2} \mathrm{O}$.
Table II. Blood Platelets and Leukocytes of Actively Sensitized Guinea Pigs either Infused Intravenously or Injected Intratracheally with Ovalbumin

\begin{tabular}{cccccc}
\hline & \multicolumn{2}{c}{ Ovalbumin i.v. } & & \multicolumn{2}{c}{ Ovalbumin i.t. } \\
\cline { 2 - 3 } \cline { 5 - 6 } Time & Platelets & Leukocytes & & Platelets & Leukocytes \\
\hline $\min$ & & & & \\
& & & & \\
1 & $97.51 \pm 4.25$ & $95.01 \pm 1.36$ & & $101.05 \pm 3.53$ & $92.16 \pm 1.89$ \\
3 & $52.67 \pm 4.54$ & $52.66 \pm 8.99$ & & $99.90 \pm 3.84$ & $78.11 \pm 1.99$ \\
5 & $30.57 \pm 6.00$ & $17.21 \pm 2.94$ & & ND & ND \\
10 & $22.92 \pm 7.58$ & $9.57 \pm 0.89$ & & $100.72 \pm 5.60$ & $92.64 \pm 3.36$ \\
30 & ND & ND & & $92.30 \pm 5.80$ & $125.54 \pm 7.15$
\end{tabular}

Counts of blood platelets and leukocytes were determined before and $1,3,5,10$, and $30 \mathrm{~min}$ after starting the infusion of ovalbumin $(0.75$ $\mathrm{mg} / \mathrm{kg}$ for $10 \mathrm{~min}, n=4)$ or after its intratracheal injection $(100 \mu \mathrm{g}$, $n=9$ ). Data are expressed in percentage of cell counts as compared to the $100 \%$ value determined before the administration of ovalbumin. Values represent mean \pm SEM.

hypotension, thrombocytopenia, or leukopenia triggered by ovalbumin (not shown).

Inhibition by LPS pretreatment of bronchoconstriction induced by the intratracheal injection of ovalbumin. To determine whether repetitive i.v. injections of LPS could affect pulmonary target(s) directly involved in the ovalbumin-induced bronchoconstriction, and to limit systemic anaphylaxis, sensitized guinea pigs were injected i.t. with ovalbumin (100 $\mu \mathrm{g}$ in $0.1 \mathrm{ml}$ saline). An abrupt bronchoconstriction appeared within 20-30 s, plateaued at $\sim 90 \mathrm{~s}$, and slowly decreased back to basal values within $60 \mathrm{~min}$ (Fig. $1 \mathrm{C}$ ). A fast and severe hypotension occurred immediately after the i.t. injection of antigen and was maximal when bronchoconstriction peaked. The decreased arterial pressure slowly normalized and was not followed by the hypertensive phase observed when ovalbumin was infused i.v. (not shown). The i.t. challenge with ovalbumin induced a mild leukopenia but no thrombocytopenia (Table II).

No further change in lung resistance to inflation was recorded when a second i.t. injection of ovalbumin was delivered $60 \mathrm{~min}$ later. In contrast, bronchoconstriction and hypotension were still triggered by an i.v. bolus of ovalbumin $(1 \mathrm{mg} / \mathrm{kg}$ in $0.1 \mathrm{ml}$ saline) injected $60 \mathrm{~min}$ after the first i.t. antigenic challenge (not shown)

Pretreatment of sensitized guinea pigs with $100 \mu \mathrm{g} / \mathrm{kg}$ LPS reduced bronchoconstriction induced by i.t. injection of ovalbumin (Fig. $1 \mathrm{D})$. A single i.v. injection $(24 \mathrm{~h})$ of LPS reduced bronchoconstriction more markedly than repetitive injections $(48,72$, or 96 h) did (Fig. 2). Single and repetitive i.v. injections of LPS failed to prevent hypotension and leukopenia induced by i.t. ovalbumin (not shown). Finally, a single dose of LPS did not modify bronchoconstriction induced by a further challenge with i.v. ovalbumin (not shown).

Pharmacological modulation of bronchoconstriction induced by the intratracheal injection of ovalbumin. Bronchoconstriction induced by i.t. injections of ovalbumin was inhibited (75\%, $P<0.01$ ) when sensitized guinea pigs were treated with mepyramine $(0.5 \mathrm{mg} / \mathrm{kg})$, a histamine $\mathrm{H}_{1}$ receptor antagonist (Fig. 3). When mepyramine was given with aspirin $(50 \mathrm{mg} / \mathrm{kg})$, a cyclooxygenase inhibitor, the ovalbumin-induced broncho- 


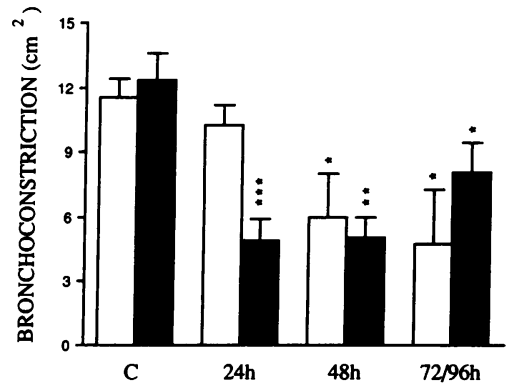

Figure 2. Time-dependent inhibition by LPS pretreatment of the ovalbumin-induced bronchoconstriction in actively sensitized guinea pigs. Ovalbumin was either infused i.v. for $10 \mathrm{~min}$ at $0.75 \mathrm{mg}$ / kg (open columns) or injected i.t. as a bolus of $100 \mu \mathrm{g}$ (closed col-

umns). Daily i.v. injections of $100 \mu \mathrm{g} / \mathrm{kg}$ LPS started $24 \mathrm{~h}, 48 \mathrm{~h}, 72$ $\mathrm{h}$, or $96 \mathrm{~h}$ before the antigenic provocation with ovalbumin. Control guinea pigs were similarly injected with saline $(1 \mathrm{ml} / \mathrm{kg})$ and are represented by column $C$. Each column represents mean \pm SEM of four to nine experiments. Vertical scale: bronchoconstriction in square centimeters (see Methods). Statistical significances $\left({ }^{*} P<0.05 ;{ }^{* *} P\right.$ $<0.01 ;{ }^{* * *} P<0.001$ ) for differences between LPS- and saline-treated guinea pigs were determined using Student's $t$ test for unpaired samples.

constriction was reduced to the same extent as mepyramine alone did (Fig. 3). Finally, the leukotriene $\mathrm{D}_{4} / \mathrm{E}_{4}$ receptor antagonist LY $171883(30 \mathrm{mg} / \mathrm{kg})$ did not significantly reduce $(29 \%$, $P>0.05$ ) the ovalbumin-induced bronchoconstriction (Fig. 3).

Although histamine is the main mediator of the antigen-induced bronchoconstriction, ovalbumin still induces bronchoconstriction in propranolol- and mepyramine-injected guinea pigs (13). To determine whether LPS modulates the histamineindependent component of antigen-induced bronchoconstriction, ovalbumin (50 $\mu \mathrm{g}$ in $0.1 \mathrm{ml}$ saline) was delivered i.t. to sensitized guinea pigs previously injected i.v. with propranolol $(1 \mathrm{mg} / \mathrm{kg})$ and mepyramine $(1 \mathrm{mg} / \mathrm{kg})$. Bronchoconstriction values of the saline-treated group $\left(16.7 \pm 7.3 \mathrm{~cm}^{2}, n=4\right)$ and of the LPS-treated group $\left(12.6 \pm 4.0 \mathrm{~cm}^{2}, n=4\right)$ were not statistically different. Together, these results led us to hypothesize that LPS modulates the histamine-dependent component of antigen-induced bronchoconstriction.

Ultrastructural evidence of mast cell degranulation in lungs from LPS-treated guinea pigs. Mast cells in the bronchial submucosa of saline-treated guinea pigs were filled with numerous heterogenous secretory granules (Fig. $4 A$ ). A single i.v. injection of LPS resulted in a loss of density of mast cell granules

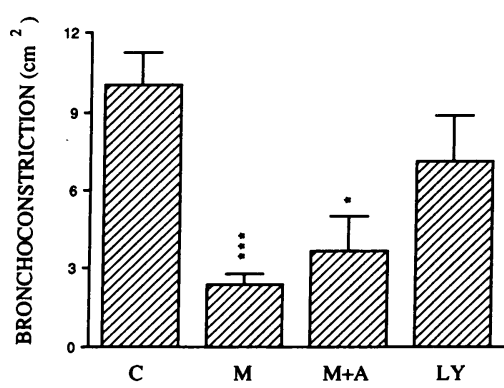

Figure 3. Involvement of histamine and peptido-leukotrienes in the ovalbumin-induced bronchoconstriction of actively sensitized guinea pigs. Mepyramine $0.5 \mathrm{mg} / \mathrm{kg}(M)$, LY $17188330 \mathrm{mg} / \mathrm{kg}$ $(L Y)$, and aspirin 50 $\mathrm{mg} / \mathrm{kg}(A)$ were injected i.v. 20,15 , and $10 \mathrm{~min}$,

respectively, before the i.t. injection of $100 \mu \mathrm{g}$ ovalbumin. Control guinea pigs were similarly injected with saline and are represented by column $C$. Each column represents the mean \pm SEM of three to five experiments. Vertical scale: bronchoconstriction in cubic centimeters (see Methods). Statistical significances $\left({ }^{*} P<0.05 ; * * * P\right.$ $<0.001$ ) for differences between drug- and saline-treated guinea pigs were determined using Student's $t$ test for unpaired samples.
(Fig. 4 B). Their number was also reduced by LPS as shown by the open areas (arrows) indicating empty granules. Moreover, free secretory granules were observed in the extracellular matrix of the bronchial submucosa from LPS-treated guinea pig lungs (Fig. $4 C$ ).

Effect of LPS on bronchoconstriction and mediator release by ovalbumin-stimulated guinea pig lungs. To provide additional evidence that a single i.v. injection of LPS affects a pulmonary target involved in the ovalbumin-induced bronchoconstriction, sensitized guinea pigs were injected i.v. on day 21 with either saline or LPS, and their lungs were exposed in vitro on day 22 to increasing doses of ovalbumin. In the salinetreated group, an intense but submaximal bronchoconstriction was already triggered by $1 \mathrm{ng}$ of ovalbumin (Fig. 5, upper panel) whereas a maximal response was evoked by the two following injections of ovalbumin (100 $\mathrm{ng}$ and $10 \mu \mathrm{g}$ ). In no case did the bronchial resistance to inflation recover its basal value in the 10-min period following each injection of ovalbumin. Pretreatment with $100 \mu \mathrm{g} / \mathrm{kg}$ of LPS markedly reduced bronchoconstriction triggered by $1 \mathrm{ng}(68 \%$ inhibition, $P<0.05)$ and 100 ng of ovalbumin ( $51 \%$ inhibition, $P<0.05$ ) but failed to reduce bronchoconstriction triggered by $10 \mu \mathrm{g}$ of antigen (Fig. 5, upper panel).

In an attempt to explain the LPS-induced reduction in antigen-induced bronchoconstriction, we measured over time the levels of $\mathrm{TXB}_{2}$ and histamine in lung effluents. In the salinetreated group, release of $\mathrm{TXB}_{2}$ and histamine was already triggered by $1 \mathrm{ng}$ of ovalbumin (Fig. 5, middle and lower panels). Histamine and $\mathrm{TXB}_{2}$ were essentially released within the first 3 min, but significant amounts of $\mathrm{TXB}_{2}$ (as compared to basal values before stimulation) were still released within the next 3 min. Nevertheless, levels of histamine and $\mathrm{TXB}_{2}$ returned to their basal values within the last minute before the following injection of ovalbumin. No significant release of both mediator was induced by $100 \mathrm{ng}$ of ovalbumin, indicating that lungs were then desensitized to ovalbumin by a previous injection of antigen (Fig. 5, middle and lower panels). Finally, $\mathrm{TXB}_{2}$ and histamine were released by $10 \mu \mathrm{g}$ of ovalbumin. However, it is noteworthy that a 10,000 -fold increase in the dose of ovalbumin resulted only in an approximate two- to threefold increase in amounts of each mediator released (Fig. 5, middle and lower panels). Pretreatment with $100 \mu \mathrm{g} / \mathrm{kg}$ of LPS markedly inhibited the release of $\mathrm{TXB}_{2}(85 \%$ inhibition, $P<0.05)$ and histamine (85\% inhibition, $P<0.01$ ) induced by $1 \mathrm{ng}$ of ovalbumin (Fig. 5, middle and lower panels) but had no effect on mediator release when $100 \mathrm{ng}$ of ovalbumin were injected. Finally, LPS pretreatment also reduced the release of $\mathrm{TXB}_{2}$ induced by 10 $\mu \mathrm{g}$ of ovalbumin ( $81 \%$ inhibition, $P<0.001$ ), but did not significantly modify the accompanying release of histamine.

Among other eicosanoids measured in lung effluents of the saline-treated group, $\mathrm{PGE}_{2}$ showed the same pattern as described above for histamine and $\mathrm{TXB}_{2}$. Release of $\mathrm{PGE}_{2}$ was triggered by $1 \mathrm{ng}$ of ovalbumin (not shown) and further evoked by $10 \mu \mathrm{g}$ of ovalbumin (Fig. 6, upper panel). In contrast, detectable amounts of 6-keto-PGF $\mathrm{PG}_{1 \alpha}, \mathrm{LTB}_{4}$, and iLTC $\mathrm{TH}_{4}$ were released only by $10 \mu \mathrm{g}$ of ovalbumin (Fig. 6, upper and lower panels). Pretreatment with LPS reduced the release of $P \mathrm{FE}_{2}$ induced by $1 \mathrm{ng}$ of ovalbumin (73\% inhibition, $P<0.05$ ) as well as the release of 6-keto- $\mathrm{PGF}_{1 \alpha}$ (73\% inhibition, $P<0.01$ ), $\mathrm{PGE}_{2}(62 \%$ inhibition, $P<0.05)$, LTB $_{4}(68 \%$ inhibition, $P<0.01)$, and iLTC $_{4}(68 \%$ inhibition, $P<0.05)$ induced by $10 \mu \mathrm{g}$ of ovalbumin (Fig. 6, upper and lower panels). 

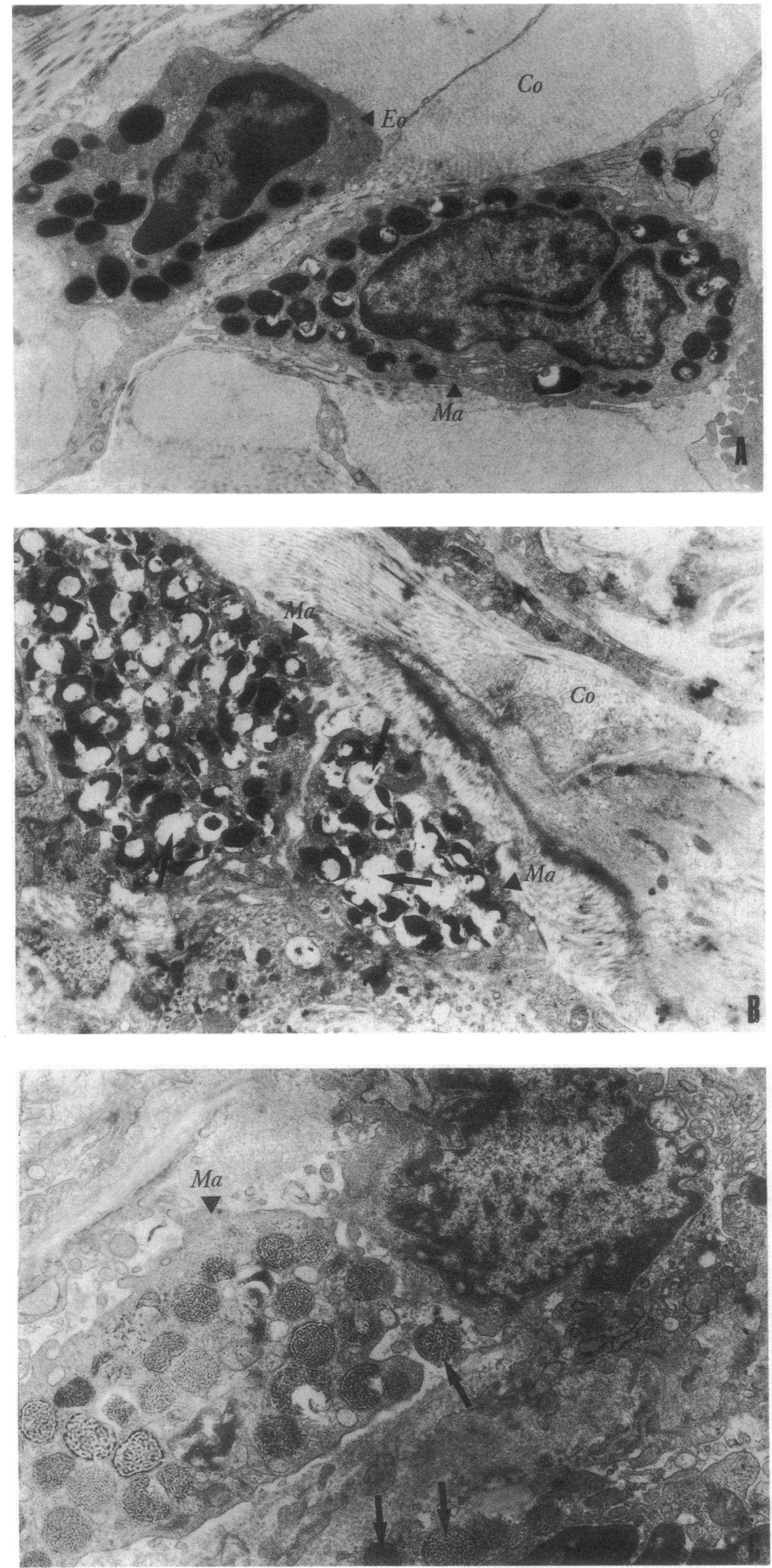

1940
Figure 4. Ultrastructural appearance of mast cells in the bronchial submucosa of guinea pigs injected with either LPS or saline. Actively sensitized guinea pigs were injected i.v. with either saline $(1 \mathrm{ml} / \mathrm{kg}, n=5)$ or LPS $(100 \mu \mathrm{g} / \mathrm{kg}, n=5)$. Lungs were isolated $24 \mathrm{~h}$ later and processed as described in Methods. (A) A mast cell from saline-treated guinea pigs, in the vicinity of an eosinophil. The cytoplasm is filled with typical heterogenous granules $(\times 10,800)$. (B) A partly degranulated mast cell from LPS-treated guinea pigs. Arrows indicate empty granules $(\times 11,500)$.

(C) Arrows indicate free secretory granules in the vicinity of a mast cell $(\times 17,800) . M a$, mastocyte; $E o$, eosinophil; $C o$, collagen; $N$, nucleus. 

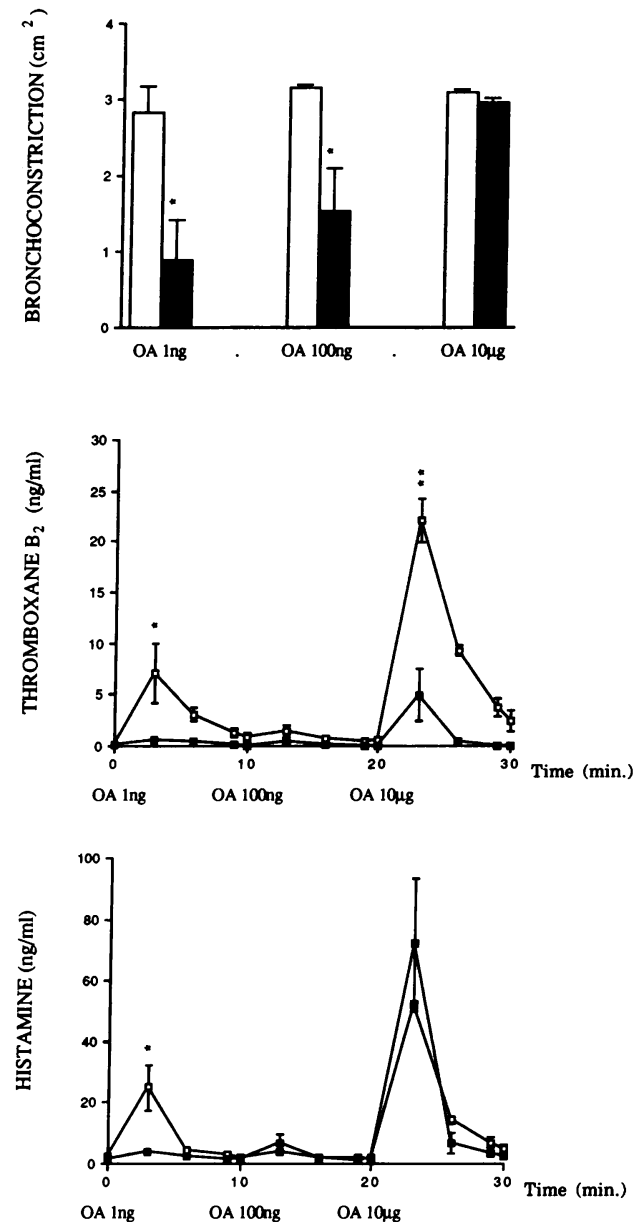

Figure 5. Effect of LPS pretreatment on bronchoconstriction and release of thromboxane $B_{2}$ and histamine by ovalbumin-stimulated guinea pig lungs. Actively sensitized guinea pigs were injected i.v. with either LPS ( $100 \mu \mathrm{g} / \mathrm{kg}, n=4$, closed columns and squares) or saline $(1 \mathrm{ml} / \mathrm{kg}, n=3$, open columns and squares). Lungs were isolated 24 $\mathrm{h}$ later and stimulated in vitro by increasing doses of ovalbumin $(O A$, $1 \mathrm{ng}, 100 \mathrm{ng}$, and $10 \mu \mathrm{g})$. Differences in bronchoconstriction as well as release of thromboxane $B_{2}$ and histamine between LPS-treated and saline-treated guinea pigs were statistically analyzed for significance $\left({ }^{*} P<0.05 ;{ }^{* *} P<0.01\right)$ using Student's $t$ test for unpaired samples.

Relationship of arachidonate metabolite production and histamine release by lungs from LPS-treated guinea pigs. Since histamine induces $\mathrm{TXA}_{2}$ production from perfused guinea pig lungs $(14,15)$, the LPS-induced reduction in $\mathrm{TXB}_{2}$ production could result from a decreased capability to release histamine. Lungs from LPS-treated guinea pigs were stimulated with histamine, and $\mathrm{TXB}_{2}$ levels were measured in lung effluents within the first $3 \mathrm{~min}$ after histamine stimulation. LPS pretreatment significantly reduced $(59 \%$ inhibition, $P<0.01)$ the release of $\mathrm{TXB}_{2}$ triggered by $10 \mathrm{ng}$ histamine $(6.92 \pm 1.05 \mathrm{ng} / \mathrm{ml}$ [saline-treated group, $n=5$ ] vs. $2.84 \pm 0.62 \mathrm{ng} / \mathrm{ml}$ [LPS-treated group, $n=5]$ ).

To clarify further if the LPS-induced reduction in histamine release and arachidonate metabolite production are separate events, lungs from LPS-treated guinea pigs were stimulated with ovalbumin in the presence of mepyramine, a histamine $H_{1}$ receptor antagonist. LPS pretreatment still reduced the release of $\mathrm{TXB}_{2}$ induced by $10 \mu \mathrm{g}$ of ovalbumin (Table III).

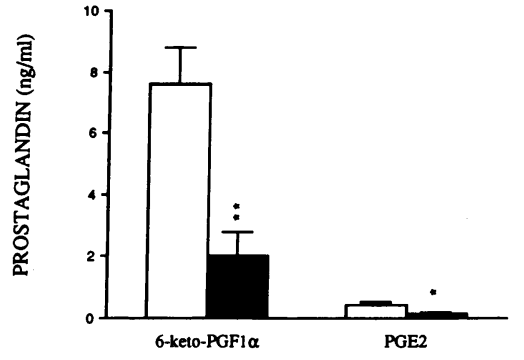

Figure 6. Effect of LPS pretreatment on release of 6-keto-PGF $1 \alpha, \mathrm{PGE}_{2}$, $\mathrm{LTB}_{4}$, and $\mathrm{iLTC}_{4}$ by ovalbumin-stimulated guinea pig lungs. Actively sensitized guinea pigs were injected i.v. with either LPS ( 100 $\mu \mathrm{g} / \mathrm{kg}, n=4$, closed columns) or saline $(1 \mathrm{ml} /$ $\mathrm{kg}, n=3$, open col-

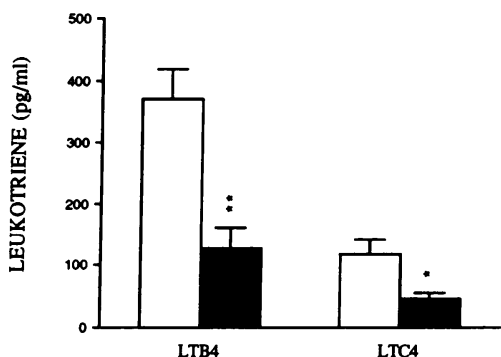
umns). Lungs were isolated $24 \mathrm{~h}$ later and stimulated in vitro by increasing doses of ovalbumin $(1 \mathrm{ng}, 100$ $\mathrm{ng}$, and $10 \mu \mathrm{g})$. Detectable amounts of each mediator were only released by $10 \mu \mathrm{g}$ of ovalbumin; mediator release within the first $3 \mathrm{~min}$ is only represented. Differences in release of 6-keto-PGF ${ }_{1 \alpha}, \mathrm{PGE}_{2}$, $\mathrm{LTB}_{4}$, and $\mathrm{iLTC}_{4}$ between LPS-treated and saline-treated guinea pigs were statistically analyzed for significance $\left({ }^{*} P<0.05 ;{ }^{* *} P<0.01\right)$ using Student's $t$ test for unpaired samples.

Effect of LPS on bronchoconstriction and mediator release by PAF- or FMLP-stimulated guinea pig lungs. To determine whether a single i.v. injection of LPS reduced bronchoconstriction and mediator release evoked by the only antigen or by non-antigen-related stimuli as well, lungs from sensitized guinea pigs were exposed to FMLP, a synthetic peptide mimicking the $\mathrm{NH}_{2}$ terminus of bacterial peptides, or to PAF, a lipid mediator released from the membrane of stimulated cells. Pretreatment with LPS failed to modify bronchoconstriction and release of $\mathrm{TXB}_{2}$ and histamine induced by $1 \mathrm{ng}$ and $100 \mathrm{ng}$ of PAF (Fig. 7). In contrast, LPS pretreatment markedly inhibited bronchoconstriction induced by $1 \mathrm{ng}(66 \%$ inhibition, $P$ $<0.05$ ) and $100 \mathrm{ng}$ of FMLP (46\% inhibition, $P<0.05$ ) (Fig. 8 , upper panel). Similarly, LPS pretreatment significantly reduced the release of $\mathrm{TXB}_{2}$ and histamine induced by $1 \mathrm{ng}(71 \%$ inhibition, $P<0.05$ ) and $100 \mathrm{ng}$ of FMLP (81\% inhibition, $P$ $<0.05$ ) (Fig. 8, middle and lower panels).

Table III. Effect of LPS Pretreatment on the Release of TXB by Ovalbumin-stimulated Guinea Pig Lungs in the Presence of Mepyramine

\begin{tabular}{lccccc}
\hline & \multicolumn{2}{c}{ Saline-treated } & & \multicolumn{2}{c}{ LPS-treated } \\
\cline { 2 - 3 } \cline { 5 - 6 } \cline { 5 - 6 } & Experiment 1 & Experiment 2 & & Experiment 3 & Experiment 4 \\
\hline Before OA* & 0.80 & 4.00 & & 0.16 & 0.13 \\
After OA & 63.00 & 33.50 & & 2.32 & 8.70 \\
& & & & & \\
\hline
\end{tabular}

Sensitized guinea pigs were injected i.v. with $100 \mu \mathrm{g} / \mathrm{kg}$ LPS. Lungs were isolated $24 \mathrm{~h}$ later as described in Methods and were perfused with Krebs-HSA containing $3 \times 10^{-6} \mathrm{M}$ mepyramine. After a 10 -min period equilibration, ovalbumin (OA, $10 \mu \mathrm{g}$ in $100 \mu \mathrm{l}$ saline) was administered via the pulmonary artery. ${ }^{*}$ Levels of $\mathrm{TXB}_{2}$ (in nanograms per milliliter) were measured in lung effluent fractions collected before and within the next 6 min after the antigenic stimulation. 

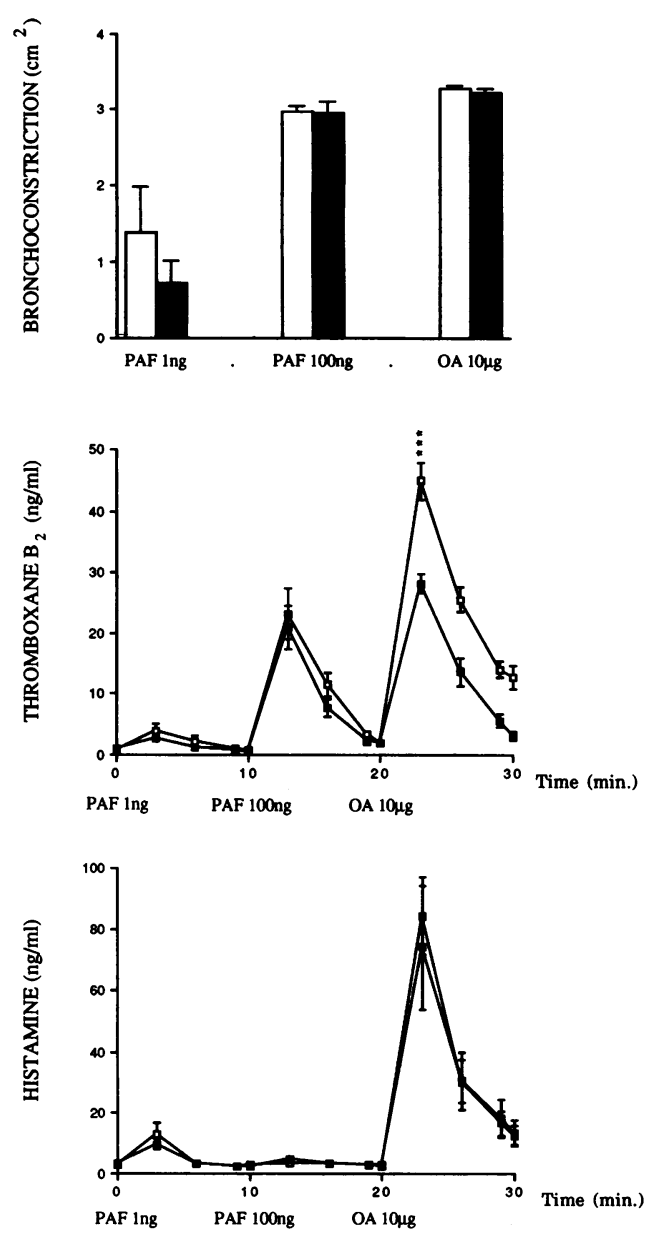

Figure 7. Effect of LPS pretreatment on bronchoconstriction and release of thromboxane $B_{2}$ and histamine by PAF-stimulated guinea pig lungs. Actively sensitized guinea pigs were injected i.v. with either LPS ( $100 \mu \mathrm{g} / \mathrm{kg}, n=7$, closed columns and squares) or saline $(1 \mathrm{ml} / \mathrm{kg}, n=5$, open columns and squares). Lungs were isolated 24 $\mathrm{h}$ later and stimulated in vitro by increasing doses of PAF $(1 \mathrm{ng}$ and $100 \mathrm{ng}$ ), followed by $10 \mu \mathrm{g}$ of ovalbumin. Differences in bronchoconstriction as well as release of thromboxane $B_{2}$ and histamine between LPS-treated and saline-treated guinea pigs were statistically analyzed for significance $\left({ }^{* * *} P<0.001\right)$ using Student's $t$ test for unpaired samples.

\section{Discussion}

In these studies, we report that a low dose of LPS from Escherichia coli reduces antigen-induced bronchoconstriction in actively sensitized guinea pigs. Injected i.v. to the guinea pig, this single dose of LPS did not itself induce an endotoxinic shock, since neither a decrease in arterial blood pressure nor vasopermeation was recorded. Nevertheless, a severe leukopenia occurred as early as $30 \mathrm{~min}$ after LPS injection, which was reversible within the first $3 \mathrm{~h}$. Moreover, LPS did not induce itself any thrombocytopenia. In contrast to LPS, nonlethal doses of infused antigen induced bronchoconstriction, a reversible hypotension, thrombocytopenia, and leukopenia. Since the protective dose of LPS activated circulating leukocytes but did not induce hypotension or vasopermeation, it is unlikely that the LPS-mediated reduction in antigen-induced bronchoconstriction results from a refractory state due to a previous endotoxinic shock.
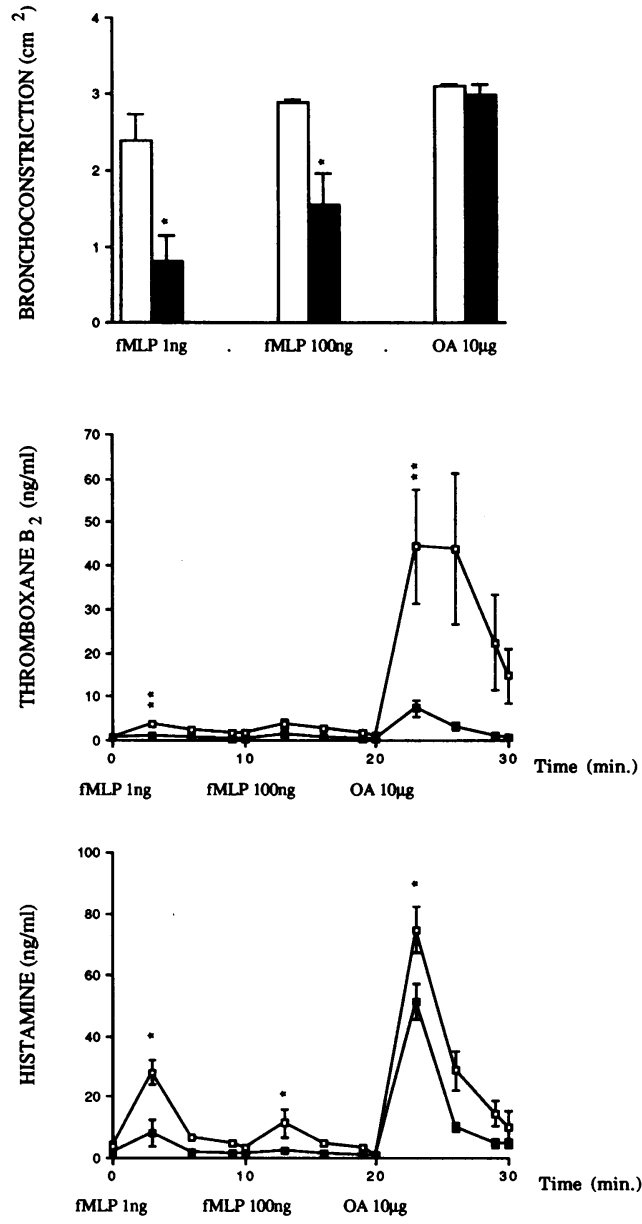

Figure 8. Effect of LPS pretreatment on bronchoconstriction and release of thromboxane $B_{2}$ and histamine by MLP-stimulated guinea pig lungs. Actively sensitized guinea pigs were injected i.v. with either LPS (100 $\mu \mathrm{g} / \mathrm{kg}, n=5$, closed columns and squares) or saline ( $1 \mathrm{ml} / \mathrm{kg}, n=4$, open columns and squares). Lungs were isolated 24 $h$ later and stimulated in vitro by increasing doses of FMLP ( $1 \mathrm{ng}$ and $100 \mathrm{ng}$ ), followed by $10 \mu \mathrm{g}$ of ovalbumin. Differences in bronchoconstriction as well as release of thromboxane $B_{2}$ and histamine between LPS-treated and saline-treated guinea pigs were statistically analyzed for significance $\left({ }^{*} P<0.05 ;{ }^{* *} P<0.01\right)$ using Student's $t$ test for unpaired samples.

In the first set of experiments, when ovalbumin was injected i.v., the protective effect of LPS was only observed for repetitive and daily injections administered over a period of 48 to $96 \mathrm{~h}$ before antigenic provocation. This lack of protection by a single dose of LPS and the involvement of systemic mediators in the antigen-induced bronchoconstriction led us to speculate that modulation of a pulmonary response triggered by the i.v. route might result from a decreased release of mediators produced both systemically and locally. Therefore, to limit the participation of histamine released from circulating basophils and from other tissues such as the liver, ovalbumin was delivered i.t. Bronchoconstriction and hypotension developed earlier than after the i.v. infusion of antigen and were not accompanied by significant modifications of the number of circulating platelets and leukocytes. In these conditions, anaphylactic bronchoconstriction was reduced by the LPS pretreatment earlier than when ovalbumin was administered i.v., suggesting that lungs from sensitized guinea pigs were already affected 
from the first day on by LPS pretreatment, irrespective of the route of ovalbumin administration.

Mepyramine markedly antagonized bronchoconstriction induced by i.v. (not shown) or i.t. ovalbumin, under conditions where neither the $\mathrm{LTD}_{4} / \mathrm{LTE}_{4}$ receptor antagonist LY171883 (16), nor the cyclooxygenase inhibitor aspirin, or PAF antagonists (17) is effective. Histamine is thus the main mediator of the in vivo bronchopulmonary response to antigen, in agreement with previous studies $(18,19)$. Histamine was also released by ovalbumin-stimulated lungs isolated from actively sensitized guinea pigs. Since in vivo anaphylactic bronchoconstriction and in vitro histamine release were both inhibited by LPS, a reduced capability of lungs from LPS-treated animals to release histamine in vivo and ex vivo in response to antigen might account for the protective effect of LPS on bronchoconstriction. Furthermore, antigen-induced bronchoconstriction in propranolol- and mepyramine-injected guinea pigs was not reduced by LPS pretreatment, supporting the hypothesis that the histamine-dependent component of the anaphylactic bronchoconstriction is the main target responsible for the protective effect of LPS. Electron microscopic studies indicated that a single dose of LPS induces a partial degranulation of the pulmonary mast cells. Nevertheless, this LPS-induced release of histamine should be protracted and subeffective, since i.v. injections of LPS did not trigger any increase in bronchial resistance to inflation. Thus, a reduced capability of lungs from LPStreated animals to release histamine due to a partial mast cell degranulation may account for the protective effect of LPS on antigen-induced bronchoconstriction.

Because it is unlikely that a single mediator, histamine, could explain all of the changes occurring in anaphylaxis, we have investigated the effect of LPS pretreatment on eicosanoid release from lungs of sensitized guinea pigs. A single dose of LPS reduced the in vitro antigen-induced production of the arachidonate metabolites $\mathrm{TXA}_{2}, \mathrm{PGE}_{2}, \mathrm{PGI}_{2}, \mathrm{LTB}_{4}$, and $\mathrm{iLTC}_{4}$. Significant reduction in release of prostaglandins and leukotrienes by isolated lungs perfused free of circulating cells suggests that resident lung cells or previously elicited cells are the likely target accounting for the LPS-induced decrease in eicosanoid production. Therefore, mast cells $(20,21)$, alveolar macrophages, eosinophils (22), and endothelial cells (23) are both the likely source of eicosanoids and a possible target of LPS pretreatment. A decreased release of TXA $\mathrm{T}_{2}$ and $\mathrm{LTC}_{4}$ may contribute to the protective effect of LPS since both TXA $\mathrm{TA}_{2}$ and $\mathrm{LTC}_{4}$ are potent bronchoconstrictors of the guinea pig lung $(24,25)$. LPS pretreatment also reduced the antigen-induced release of $\mathrm{LTB}_{4}$, a less potent bronchoconstrictor of guinea pig lung than $\mathrm{LTC}_{4}(25)$. Release of the bronchorelaxant $\mathrm{PGE}_{2}$ was reduced by LPS pretreatment, ruling out a direct regulatory effect of $\mathrm{PGE}_{2}$ on smooth muscle contraction (26) as a possible explanation for the protective effect of LPS. Finally, the production of $\mathrm{PGI}_{2}$ was also reduced by LPS pretreatment, indicating that endothelial cells of the pulmonary vasculature were affected by LPS. The decrease in production of eicosanoids after a long-term exposure to LPS is in sharp contrast with the shortterm priming effect of LPS on eicosanoid synthesis by inflammatory cells $(27,28)$ or perfused lungs $(29)$.

Since histamine induces $\mathrm{TXA}_{2}$ formation from perfused guinea pig lungs $(14,15)$, the release of histamine may be the rate-limiting step for a subsequent formation of arachidonate metabolites. In our studies, LPS pretreatment suppressed the release of $\mathrm{TXB}_{2}$ triggered either by histamine itself or ovalbumin in the presence of mepyramine, a histamine $\mathrm{H}_{1}$ receptor antagonist. Moreover, LPS pretreatment suppressed the formation of $\mathrm{TXA}_{2}, \mathrm{PGE}_{2}, \mathrm{PGI}_{2}, \mathrm{LTB}_{4}$, and $\mathrm{iLC}_{4}$, but failed to reduce release of histamine induced by $10 \mu \mathrm{g}$ ovalbumin. These results suggest that inhibition of histamine release and $\mathrm{TXB}_{2}$ formation by LPS are separate events, even though the LPS-induced decrease in histamine release may contribute to the reduction in arachidonate metabolite production. Furthermore, a decreased production of both cyclooxygenase and lipoxygenase products suggests that a proximal step in the cyclooxygenase and lipoxygenase pathways, such as availability of arachidonic acid, may be the limiting step affected by LPS pretreatment. Although LPS has been reported to increase phospholipase $\mathrm{A}_{2}$ (PLA $)$ activity in rat lungs (30) and rabbit peritoneum (31), a decreased PLA $\mathrm{A}_{2}$ activity is thought to be a subcellular mechanism accounting for an increase in airways hyperreactivity of guinea pig trachea $4 \mathrm{~d}$ after LPS injection (32). Therefore, it is possible that an early LPS-induced increase in PLA $\mathrm{A}_{2}$ activity is followed by a decrease of a stimuli-induced PLA $\mathrm{P}_{2}$ activity, explaining the reduced capability of pulmonary cells to generate prostaglandins and leukotrienes after LPS pretreatment.

The LPS-induced protection was not antigen-specific, since the FMLP-induced bronchoconstriction and release of histamine and $\mathrm{TXB}_{2}$ were also reduced. Previous studies have shown that FMLP-induced chemotactic response and superoxide generation of rabbit PMNs are not affected by in vivo LPS pretreatment (33), although LPS induced an increase in FMLP receptor density (34). Such an uncoupling of receptors for FMLP might also explain the protective effect of LPS on the FMLP-induced pulmonary responses, in our model. The protective effect of LPS is unlikely to result from a general desensitization since PAF-induced bronchoconstriction and release of histamine and $\mathrm{TXB}_{2}$ were not inhibited by LPS pretreatment. From these results, it could also be stressed that different pathways lead to activation of lung cells by PAF, FMLP, and ovalbumin. Moreover, the lack of protective effect of LPS on the PAF-induced histamine release reinforces the concept of a partial degranulation of pulmonary mast cells upon injection of LPS.

Our findings indicate that a single dose of LPS reduces the antigen-induced bronchoconstriction in actively sensitized guinea pigs. The histamine-dependent component appears to be the main target accounting for the protective effect of LPS. Moreover, the LPS-induced decrease in histamine release and eicosanoid production are separate events, suggesting that LPS might also be protective in inflammatory reactions where eicosanoids play a major role. Our surprising results lead us to conclude that the protective effect of LPS may counteract its well-known priming effect on inflammatory reactions. Such dual effect of LPS may modulate pulmonary allergic reactions, frequently associated with inflammation, or even bacterial infections. LPS is a potent inducer of IL-1, and a single low dose of IL-1 has been reported to inhibit inflammation in rabbit colitis (35), antigen-induced arthritis in rats (36), and contact hypersensitivity responses in mice (37). Further investigations will indicate whether IL-1, or other cytokines with histaminereleasing activities, mediates the protective effect of LPS on antigen-induced pulmonary responses.

\section{Acknowledgments}

The authors thank Michèle Laurent and Annick Leroy (Unité d'Immuno-Allergie, Institut Pasteur, Paris, France) for histamine determinations, and Claude Ruffié for her help in measuring $\mathrm{TXB}_{2}$.

Edouard Vannier is supported by Rhône-Poulenc Rorer. 


\section{References}

1. Brigham, K. L., and B. Meyrick. 1986. Endotoxin and lung injury. Am. Rev. Respir. Dis. 133:913-927.

2. Chang, S. W., J. Y. Wescott, W. C. Pickett, R. C. Murphy, and N. F. Voelkel. 1989. Endotoxin-induced lung injury in rats: role of eicosanoids. J. Appl. Physiol. 66:2407-2418.

3. Worthen, G. S., C. Haslett, A. J. Rees, R. S. Gumbay, J. E. Henson, and P. M. Henson. 1987. Neutrophil-mediated pulmonary vascular injury. Synergistic effects of trace amounts of lipopolysaccharide and neutrophil stimuli on vascular permeability and neutrophil sequestration in the lung. Am. Rev. Respir. Dis. 136:19-28.

4. Urbaschek, B., B. Ditter, K. P. Becker, and R. Urbaschek. 1984. Protective effects and role of endotoxin in experimental septicemia. Circ. Shock. 14:209222.

5. Rosenbaum, J. T., K. T. Hartiala, R. O. Webster, E. L. Howes, and I. M. Goldstein. 1983. Antiinflammatory effects of endotoxin. Inhibition of rabbit polymorphonuclear leukocyte responses to complement $\left(C_{5}\right)$-derived peptides in vivo and in vitro. Am. J. Pathol. 113:291-299.

6. Smith, M. J. H., A. W. Ford-Hutchinson, and J. R. Walker. 1977. Anti-inflammatory activity of bacterial endotoxin. J. Pharm. Pharmacol. 29:702-704.

7. Rocha, N. P., and S. H. Ferreira. 1986. Restoration by levamisole of endotoxin-inhibited neutrophil migration, oedema and increased vascular permeability induced by carrageenin. Eur. J. Pharmacol. 122:87-92.

8. Rosenbaum, J. T., and R. B. Mandell. 1983. The effect of endotoxin and endotoxin tolerance on inflammation induced by mycobacterial adjuvant. Yale J. Biol. Med. 56:293-301.

9. Meier, R., H. J. Bein, and R. Jaques. 1957. The action of bacterial polysaccharides on allergic phenomena. Int. Arch. Allergy Appl. Immunol. 11:101-118.

10. Westphal, O., and K. Jann. 1965. Bacterial lipopolysaccharides. Extraction with phenol-water and further applications of the procedure. Methods Carbohydr. Chem. 5:83-91.

11. Lefort, J., and B. B. Vargaftig. 1978. Role of platelets in aspirin-sensitive bronchoconstriction in the guinea pig: interactions with salicylic acid. Br. J. Pharmacol. 63:35-42.

12. Lebel, B. 1983. A high-sampling-rate automated continuous-flow fluorimetric technique for the analysis of nanogram levels of histamine in biological samples. Anal. Biochem. 133:16-29.

13. Garcez do Carmo, L., R. Cordeiro, V. Lagente, J. Lefort, J. Randon, and B. B. Vargaftig. 1986. Failure of a combined anti-histamine and anti-leukotriene treatment to suppress passive anaphylaxis in the guinea-pig. Int. J. Immunopharmacol. 8:985-995.

14. Berti, F., G. C. Folco, A. Giachetti, S. Malandrino, C. Omini, and T. Vigano. 1980. Atropine inhibits thromboxane $A_{2}$ generation in isolated lungs of the guinea-pig. Br. J. Pharmacol. 68:467-472.

15. Pretolani, M. J. Lefort, and B. B. Vargaftig. 1988. Active immunization induces lung hyperresponsiveness in the guinea-pig. Pharmacologic modulation and triggering role of the booster injection. Am. Rev. Respir. Dis. 138:1572-1578.

16. Fleisch, J. H., L. E. Rinkema, K. D. Haisch, D. Swanson-Bean, T. Goodson, P. P. K. Ho, and W. S. Marshall. 1985. LY171883, 1-<2-hydroxy-3-propyl4-<4- (1 H-tetrazol-5-yl) butoxy >phenyl >ethanone, an orally active leukotriene D, antagonist. J. Pharmacol. Exp. Ther. 233:148-157.

17. Desquand, S., J. Lefort, C. Dumarey, and B. B. Vargaftig. 1990. The booster injection of antigen during active sensitization of guinea-pig modifies the anti-anaphylactic activity of the PAF antagonist WEB 2086. Br. J. Pharmacol. 100:217-222.

18. Anderson, W. H., M. O'Donnel, B. A. Simko, and A. F. Welton. 1983. An in vivo model for measuring antigen-induced SRS-A mediated bronchoconstriction and plasma SRS-A levels in the guinea-pig. Br. J. Pharmacol. 78:67-74.
19. Daffonchio, L., I. W. Lees, A. N. Payne, and B. J. R. Whittle. 1987. Pharmacological modulation of bronchial anaphylaxis induced by aerosol challenge in anaesthetized guinea-pigs. Br. J. Pharmacol. 91:701-708.

20. MacGlashan, D. W., Jr., R. P. Schleimer, S. P. Peters, E. S. Schulman, G. K. Adams III, H. H. Newball, and L. M. Lichtenstein. 1982. Generation of leukotrienes by purified human lung mast cells. J. Clin. Invest. 70:747-751.

21. Undem, B. J., J. B. Brendel, T. Hirth, C. K. Buckner, and F. M. Graziano. 1986. Comparative studies of mediator release from guinea pig lung mast cells and basophils. Am. Rev. Respir. Dis. 133:763-768.

22. Hirata, K., K. Maghni, P. Borgeat, and P. Sirois. 1990. Guinea-pig alveolar eosinophils and macrophages produce leukotriene $B_{4}$ but no peptido-leukotriene. J. Immunol. 144:1880-1885.

23. Schulman, E. S., H. H. Newball, L. M. Demers, F. A. Fitzpatrick, and N. F. Adkinson. 1981. Anaphylactic release of thromboxane $A_{2}$, prostaglandin $\mathrm{D}_{2}$, and prostacyclin from human lung parenchyma. Am. Rev. Respir. Dis. 124:402-406.

24. Moncada, S., and J. R. Vane. 1979. Pharmacology and endogenous roles of prostaglandin endoperoxides, thromboxane $\mathrm{A}_{2}$, and prostacyclin. Pharmacol. Rev. 30:293-331.

25. Samuelsson, B. 1983. Leukotrienes: mediators of immediate hypersensitivity reactions and inflammation. Science (Wash. DC). 220:568-575.

26. Wasserman, M. A., R. L. Griffin, and F. B. Marsali. 1980. Inhibition of bronchoconstriction by aerosols of prostaglandins $\mathrm{E}_{1}$ and $\mathrm{E}_{2}$. J. Pharmacol. Exp. Ther. 214:68-73.

27. Aderem, A. A., D. S. Cohen, S. D. Wright, and Z. A. Cohn. 1986. Bacterial lipopolysaccharides prime macrophages for enhanced release of arachidonic acid metabolites. J. Exp. Med. 164:165-179.

28. Doerfler, M. E., R. L. Danner, J. H. Shelhamer, and J. E. Parrillo. 1989. Bacterial lipopolysaccharides prime human neutrophils for enhanced production of leukotriene $B_{4}$. J. Clin. Invest. 83:970-977.

29. Salzer, W. L., and C. E. McCall. 1990. Primed stimulation of isolated perfused rabbit lung by endotoxin and platelet activating factor induces enhanced production of thromboxane and lung injury. J. Clin. Invest. 85:1135-1143.

30. Von Wichert, P., M. Temmesfeld, and W. Meyer. 1981. Influence of septic shock upon phosphotidylcholine remodeling mechanisms in rat lung. Biochim. Biophys. Acta. 664:487-497.

31. Bult, H., and A. G. Herman. 1983. Influence of endotoxin on arachidonate metabolism in isolated rabbit peritoneum. Biochem. Pharmacol. 32:25232528 .

32. Folkerts, G., F. Engels, and F. P. Nijkamp. 1989. Endotoxin-induced hyperreactivity of the guinea-pig isolated trachea coincides with decreased prostaglandin $\mathrm{E}_{2}$ production by the epithelial layer. Br. J. Pharmacol. 96:388-394.

33. Hartiala, K. T. L. Langlois, I. M. Goldstein, and J. T. Rosenbaum. 1985. Endotoxin-induced selective dysfunction of rabbit polymorphonuclear leukocytes in response to endogenous chemotactic factors. Infect. Immun. 50:527-533.

34. Goldman, D. W. H. Enkel, L. A. Gifford, D. E. Chenoweth, and J. T. Rosenbaum. 1986. Lipopolysaccharide modulates receptors for leukotriene $B_{4}$, $\mathrm{C}_{5 n}$, and formyl-methionyl-leucyl-phenylalanine on rabbit polymorphonuclear leukocytes. J. Immunol. 137:1971-1976.

35. Cominelli, F., C. C. Nast, R. Llerena, C. A. Dinarello, and R. D. Zipser. 1990. Interleukin 1 suppresses inflammation in rabbit colitis. Mediation by endogenous prostaglandins. J. Clin. Invest. 85:582-586.

36. Jacobs, C., D. Young, S. Tyler, G. Callis, S. Gillis, and P. J. Conlon. 1988. In vivo treatment with IL-1 reduces the severity and duration of antigen-induced arthritis in rats. J. Immunol. 141:2967-2974.

37. Robertson, B., L. Gahring, R. Newton, and R. Daynes. 1987. In vivo administration of interleukin-1 to normal mice depresses their capacity to elicit contact hypersensitivity responses: prostaglandins are involved in this modification of immune function. J. Invest. Dermatol. 88:380-387. 